\title{
Molecular surveillance of anti-malarial drug resistance in Democratic Republic of Congo: high variability of chloroquinoresistance and lack of amodiaquinoresistance
}

Doudou M. Yobi ${ }^{1 *}$, Nadine K. Kayiba ${ }^{2,3}$, Dieudonné M. Mvumbi ${ }^{1}$, Raphael Boreux ${ }^{4}$, Pius Z. Kabututu', Hippolyte N. T. Situakibanza ${ }^{5}$, Joris L. Likwela ${ }^{6}$, Patrick De Mol ${ }^{4}$, Emile W. Okitolonda ${ }^{\wedge}{ }^{\wedge}$, Niko Speybroeck ${ }^{3}$, Georges L. Mvumbi ${ }^{1}$ and Marie-Pierre Hayette ${ }^{4}$

\begin{abstract}
Background: The loss of chloroquine (CQ) effectiveness has led to its withdrawal from national policies as a first-line treatment for uncomplicated malaria in several endemic countries, such as the Democratic Republic of Congo (DRC). The K76T mutation on the pfcrt gene has been identified as a marker of CQ resistance and the SVMNT haplotype in codons 72-76 on the same gene has been associated with resistance to amodiaquine (AQ). In the DRC, the prevalence of K76T has decreased from 100\% in 2000 to 63.9\% in 2014. The purpose of this study was to determine the prevalence of K76T mutations in circulating strains of Plasmodium falciparum, 16 years after CQ withdrawal in the DRC and to investigate the presence of the SVMNT haplotype.

Methods: In 2017, ten geographical sites across the DRC were selected. Dried blood samples were collected from patients attending health centres. Malaria was first detected by a rapid diagnostic test (RDT) available on site (SD Bioline Malaria Ag Pf or CareStart Malaria Pf) or thick blood smear and then confirmed by a P. falciparum species-specific real-time PCR assay. A pfcrt gene segment containing a fragment that encodes amino acids at positions $72-76$ was amplified by conventional PCR before sequencing.

Results: A total of 1070 patients were enrolled. Of the 806 PCR-confirmed P. falciparum positive samples, 764 were successfully sequenced. The K76T mutation was detected in 218 samples (28.5\%; 95\% Cl 25.4\%-31.9\%), mainly (96\%) with the CVIET haplotype. Prevalence of CQ resistance marker was unequally distributed across the country, ranging from 1.5\% in Fungurume to $89.5 \%$ in Katana. The SVMNT haplotype, related to AQ resistance, was not detected.

Conclusion: Overall, the frequency of the P. falciparum CQ resistance marker has decreased significantly and no resistance marker to $A Q$ was detected in the DRC in 2017. However, the between regions variability of CQ resistance remains high in the country. Further studies are needed for continuous monitoring of the CQ resistance level for its prospective re-use in malaria management. The absence of the $A Q$ resistance marker is in line with the use of this drug in the current DRC malaria treatment policy.
\end{abstract}

\footnotetext{
*Correspondence: doudou.yobi@unikin.ac.cd

^Emile W. Okitolonda_Passed away on October 29th, 2019

1 Department of Basic Sciences, Faculty of Medicine, University of Kinshasa, Kinshasa, Democratic Republic of Congo

Full list of author information is available at the end of the article
}

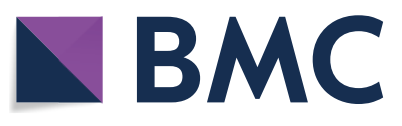

(c) The Author(s) 2020. This article is licensed under a Creative Commons Attribution 4.0 International License, which permits use, sharing, adaptation, distribution and reproduction in any medium or format, as long as you give appropriate credit to the original author(s) and the source, provide a link to the Creative Commons licence, and indicate if changes were made. The images or other third party material in this article are included in the article's Creative Commons licence, unless indicated otherwise in a credit line to the material. If material is not included in the article's Creative Commons licence and your intended use is not permitted by statutory regulation or exceeds the permitted use, you will need to obtain permission directly from the copyright holder. To view a copy of this licence, visit http://creativeco mmons.org/licenses/by/4.0/. The Creative Commons Public Domain Dedication waiver (http://creativecommons.org/publicdomain/ zero/1.0/) applies to the data made available in this article, unless otherwise stated in a credit line to the data. 
Keywords: Molecular, Surveillance, Resistance, Chloroquine, Amodiaquine, DRC

\section{Background}

Plasmodium falciparum, which is the most common and deadly Plasmodium species in sub-Saharan Africa, has developed resistance mechanisms to almost all existing anti-malarial drugs with a significant impact on malaria control. The World Health Organization (WHO) recommends monitoring the therapeutic efficacy of anti-malarials used in the treatment of uncomplicated $P$. falciparum malaria every 2 years. Beyond a $10 \%$ resistance rate, the WHO recommendation is to replace the drug with a more effective one [1]. The gradual decline in the therapeutic efficacy of chloroquine (CQ) has led to its withdrawal from the uncomplicated malaria treatment of $P$. falciparum in endemic countries. In the Democratic Republic of Congo (DRC), a clinical study conducted in 2001 to evaluate CQ effectiveness reported a treatment failure rate of $45.5 \%$ [2]. This high failure rate led to the replacement of CQ by the combination sulfadoxine-pyrimethamine (SP) in the management of uncomplicated malaria [2]. In 2005, due to the decreasing efficacy of the current treatments, the DRC adopted the use of artemisinin-based combination therapy (ACT) as the first-line treatment for uncomplicated malaria. Artesunate-amodiaquine (ASAQ) has been the mainstay of the country's ACT anti-malarial drug policy since the implementation of $\mathrm{ACT}$ in the DRC. Artemether-lumefantrine (AL) was added as an alternative to ASAQ later in 2012. Both ASAQ and AL are now concurrently used in the treatment of uncomplicated $P$ falciparum malaria in the DRC [3]. To explain clinical resistance to these antimalarial drugs, molecular studies have been conducted and have identified mutations on several genes such as the $p f c r t$ gene which encodes a membrane transporter protein located on the parasitic digestive vacuole in $P$. falciparum $[4,5]$. The $p f c r t$ gene is highly polymorphic, however the gene variant coding the PFCRT protein in which lysine $(\mathrm{K})$ is replaced by threonine $(\mathrm{T})$ at position $76(\mathrm{~K} 76 \mathrm{~T})$ is responsible for a lack of CQ accumulation in the digestive vacuole leading to resistance [5-9]. The majority of $p f c r t$ gene mutations related to CQ resistance were localized between codons 72 and 76, determining different phenotypic profiles. CVMNK is the wild haplotype in CQ-sensitive parasites, whereas the CVIET, SVMNT, SVIET, CVMNT and CVTNT haplotypes are classically associated with CQ resistance [10]. The SVMNT haplotype was found to also be associated with resistance to amodiaquine (AQ), one of the components of some artemisinin-based combinations
[11]. This haplotype has been reported in some neighbouring countries such as Tanzania and Angola, but not yet in the DRC $[12,13]$.

The prevalence of the K76T mutation has evolved considerably since the withdrawal of $\mathrm{CQ}$ from the management policy in several endemic countries. Studies have reported a decrease in the $\mathrm{K} 76 \mathrm{~T}$ mutation prevalence in some African countries such as Rwanda, the Republic of Congo and Kenya [14-17], whereas this prevalence remained high in other countries such as Ghana and Ethiopia several years after CQ withdrawal $[18,19]$. The 2007 national Demographic Health Survey (DHS) reported a prevalence of $55.4 \%$ for the K76T mutation in the DRC [20]. This prevalence was $73.2 \%$ in a study conducted in Kinshasa in 2010 [21] and 63.9\% in a study conducted in 2014 in 6 provinces of the DRC [22]. No marker of resistance to $\mathrm{AQ}$ has yet been reported in the DRC. The purpose of the present study was to determine the prevalence of the K76T mutation 16 years after CQ withdrawal from treatment policy and to investigate the presence of the SVMNT haplotype in the DRC.

\section{Methods \\ Study area}

The study was conducted in collaboration with the National Malaria Control Programme (NMCP). Ten sites were selected among the 26 provinces of the DRC. The study included the 3 largest cities of the country (Kinshasa, Kisangani and Lubumbashi) as well as 7 other sites that were selected based on their epidemiological facies, which refers to the malaria transmission intensities [23]. Thus, the following sites were selected: Bolenge, Karawa and Vanga for the equatorial facies characterized by high and permanent transmission; Kalima, Kamina and Fungurume for the tropical facies marked by seasonal variations with resurgences during the rainy season (8-9 months) and Katana for the mountainous facies with low transmission. Figure 1 presents a map of study sites according to the selection criteria. All collection sites are NMCP's sentinel sites for malaria surveillance, except Lubumbashi. These sentinel sites are organized within one selected Health Zone entity, per province, and are part of a national network for malaria surveillance. The objectives of this network are to provide accurate, real-time data on morbidity-mortality trends, monitor the epidemiological progression for a rapid response, monitor and evaluate control interventions and progress towards the elimination of malaria. A pilot study was conducted first in Kinshasa from January to March 2017. 


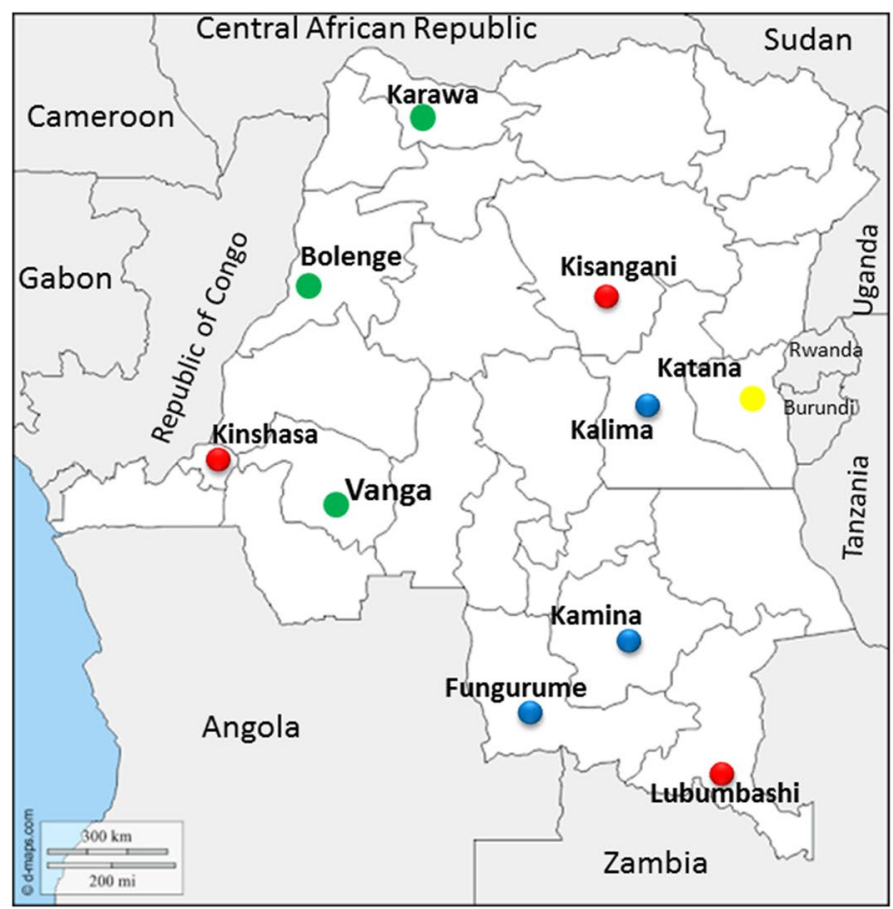

Largest cities

- Sites with equatorial facies

Sites with tropical facies

Sites with mountainous facies

Fig. 1 Map of study sites across the Democratic Republic of Congo (DRC)

Afterwards, the study was started in the other sites from September to December 2017.

\section{Study participants}

Patients of all ages who attended one of the selected medical centres for fever and who had a positive rapid diagnostic test (RDT) for malaria or a positive thick blood smear were enrolled after informed consent was given.

\section{Blood sample collection}

Screening tests were performed on blood samples taken by finger prick. RDTs were used depending on the availability of the test on site. Two RDTs were available which detected both P. falciparum HRP2 protein: the SD Bioline Malaria Ag Pf (Standard Diagnostics) assay was used to enroll patients attending all collection sites except in Kinshasa, where the CareStart Malaria Pf (Access Bio) assay was used in the majority of patients. In cases of a lack of RDTs, a positive thick blood smear test for malaria was performed for enrollment.

After enrollment, a blood sample was taken by finger prick and three spots were deposited on Whatman Grade GB003 filter paper (Whatman, GE Healthcare). Dried blood spots (DBS) were placed in an individual ziploc plastic bag containing silica gel desiccant and were then stored at room temperature before their transfer to the
Clinical Microbiology Laboratory of the University of Liège for molecular analysis.

\section{DNA extraction}

DNA was extracted from blood spots using the QIAamp DNA Mini Kit (Qiagen, Germany) following the recommended protocol for DBS. The extracted DNA was stored at $-20^{\circ} \mathrm{C}$ before PCR testing.

\section{Plasmodium falciparum real-time PCR}

A real-time PCR for the detection of P. falciparum was performed according to a modified procedure previously described [24]. Briefly, the mix contained $200 \mathrm{nM}$ of $P$. falciparum primers and probe, a volume of $2.5 \mu \mathrm{l}$ of Double-Dye Probe/Primer for Internal Positive Control (IPC), $2.5 \mu \mathrm{l}$ of DNA virus culture (DIA-EIC/DNACy5) for IPC, $12.5 \mu \mathrm{l}$ of $2 \times$ Taqman Universal PCR Master Mix (Applied Biosystems) and water to reach a total volume of $25 \mu \mathrm{l}$ including $5 \mu \mathrm{l}$ of DNA template. Assays were run on an ABI 7500 Fast real-time thermocycler (Applied Biosystems).

\section{pfcrt PCR}

The fragment of interest (containing codons 72-76) on the pfcrt gene was amplified following a previously described procedure [21]. The PCR was run on a conventional Dyad Peltier Thermal Cycler (Bio-Rad 
Laboratories, CA, US). The PCR products were visualized after electrophoresis on $2 \%$ agarose gel stained with ethidium bromide.

\section{pfcrt genotyping}

After purification using AMPure XP magnetic beads (Beckman Coulter, CA, US), the PCR products were added to a mix of Big Dye Terminator V3.1 for the sequencing reaction. The resulting 152-bp nucleotide sequences were analysed on an ABI 3730 DNA Analyzer automated sequencer (Applied Biosystems) using the Sanger method at GIGA, the interdisciplinary biomedical research centre of Liège University. These 152bp nucleotide fragments of the pfcrt gene encompassing the codons at position 72-76, were aligned using GeneStudio $^{\mathrm{TM}}$ Professional and compared to the reference sequence PF3D7_0709000 (https://www.ncbi.nlm.nih. gov/gene/term=PF3D7_0709000 accessed on September 11, 2018) using the online Basic Local Alignment Search Tool (BLAST) for identifying mutations.

\section{Ethical considerations}

The protocol and the informed consent form were approved by the Ethics Committee of the Faculty of Medicine, University of Kinshasa (Approval No: ESP MINESU 019/2016). All participants involved in the study signed an informed consent form. Where participants were young (children), the consent form was approved and signed by their parents or guardians.

\section{Statistical analysis}

Data were entered in an Excel 2010 database by an independent data clerk. Statistical analysis was performed using SPSS V. 20.0 (IBM corp., Armonk, NY). The pfcrt genotype profile was determined by the absence or presence of wild/mutant alleles. Samples for which the genotype profile could not be determined were excluded from the analysis. Difference between sites was assessed using the Chi square test for proportions and a $p$ value of less than 0.05 was considered statistically significant.

\section{Results}

In total, 1070 patients were enrolled in the study, their age ranged from 0 to 74 years. Table 1 presents the distribution of patients per age range: children aged from 0 to 5 years were the most affected age category.

Real-time PCR analysis of DNA extracted from DBS samples confirmed the initial diagnosis of $P$. falciparum infection for 806 (75.3\%) patients. Of the 764 successfully sequenced $P$. falciparum isolates, 218 (28.5\%) carried the K76T mutation known to confer resistance to CQ. Table 2 reports the prevalence of K76T mutations in different collection sites in the DRC. The highest rate
Table 1 Distribution of study patients per age range

\begin{tabular}{lcl}
\hline Age range (year) & Effective & Frequency \% (95\% Cl) \\
\hline $0-5$ & 465 & $43.5(40.5-46.5)$ \\
$6-14$ & 281 & $26.3(23.7-29.0)$ \\
$15-49$ & 285 & $26.6(24.0-29.4)$ \\
$50-74$ & 39 & $3.6(2.6-5.0)$ \\
Total & 1070 & 100 \\
\hline
\end{tabular}

(89.5\%) was detected in Katana, in the eastern province of Sud-Kivu, and the lowest rate (1.5\%) in Fungurume, in the southeastern province of Lwalaba. Globally, a significant difference was observed between all study sites $(p<0.001)$. Figure 2 shows the distribution of K76T mutations across the DRC. Four out of ten sites (Kinshasa, Bolenge, Vanga and Katana) showed a K76T prevalence rate higher than $30 \%$.

Table 3 shows the CQ-resistant PFCRT 72-76 haplotypes that were detected in each study site; the CVIET haplotype was predominant in isolates carrying K76T mutations (95.9\%). The CQ-sensitive CVMNK haplotype was found in wild-type $P$. falciparum isolates, while the SVMNT haplotype associated with AQ resistance was not detected in the present study.

\section{Discussion}

This study was conducted in ten different sites across the DRC for monitoring molecular resistance of $P$. falciparum to $\mathrm{CQ}$ and to $\mathrm{AQ}$. The study has shown that 16 years after official CQ withdrawal from the national treatment policy, CQ-resistance prevalence has decreased in DRC to $28.5 \%$ and is marked by a high variability from site to site that was found to be significantly different $(\mathrm{p}<0.001)$. No molecular marker of $\mathrm{AQ}$ resistance has been found.

A decline in the prevalence of resistance has also been reported in several other African countries. An in vivo assay conducted in 2005 [25] revealed a return of CQ efficacy to $99 \%$ in Malawi, the first country to change its national first-line malaria treatment policy from CQ to $\mathrm{SP}$ in 1993. More studies have shown the return of efficacy for CQ several years after its withdrawal from treatment policies. In Tanzania, CQ resistance decreased from $80 \%$ in 2001 to $5.7 \%$ in 2011 [26]. In Kenya, it decreased from 76 to $6 \%$ between 2003 and 2015 [27]. In the Republic of Congo (Brazzaville), resistance decreased from $100 \%$ in 2005,1 year before the introduction and implementation of ACT in 2006, to 71\% in 2015 [14]. In Zambia, no CQ resistance marker was detected in a clinical trial conducted from 2010 to 2013 [28].

The relationship between drug pressure and CQ sensitivity has been clearly reported by Feng et al. and Frosch et al. $[16,29]$. When the pressure stops, the drug tends 
Table 2 Prevalence of K76T mutation per study site

\begin{tabular}{|c|c|c|c|c|c|}
\hline Site & $\begin{array}{l}\text { Positive RDT/thick } \\
\text { blood sample } \\
\mathrm{N}\end{array}$ & $\begin{array}{l}\text { Positive Pf PCR } \\
\mathrm{N}(\%)\end{array}$ & $\begin{array}{l}\text { Samples successfully } \\
\text { sequenced among positive } \\
\text { Pf PCR } \\
\text { N }\end{array}$ & $\begin{array}{l}\text { Samples with K76T } \\
\text { mutant } \\
N\end{array}$ & $\begin{array}{l}\text { Prevalence of K76T } \\
\text { mutation } \%(95 \% \mathrm{Cl})\end{array}$ \\
\hline Bolenge & 98 & $73(74.5)$ & 56 & 18 & $32.1(20.3-46.6)$ \\
\hline Fungurume & 92 & 65 (70.7) & 65 & 1 & $1.5(0.0-8.3)$ \\
\hline Kalima & 97 & $67(69.1)$ & 66 & 3 & $4.5(0.9-12.7)$ \\
\hline Kamina & 98 & $73(74.5)$ & 71 & 8 & $11.3(5.0-21.0)$ \\
\hline Karawa & 97 & $66(68.0)$ & 54 & 6 & $11.1(4.2-22.6)$ \\
\hline Katana & 105 & $78(74.3)$ & 76 & 68 & $89.5(80.3-95.3)$ \\
\hline Kinshasa & 160 & $160(100)$ & 160 & 78 & $48.8(40.8-56.8)$ \\
\hline Kisangani & 128 & $93(72.7)$ & 85 & 4 & $4.7(1.3-11.6)$ \\
\hline Lubumbashi & 101 & $56(55.4)$ & 56 & 1 & $1.8(0.0-9.6)$ \\
\hline Vanga & 94 & 75 (79.8) & 75 & 31 & $41.3(30.1-53.3)$ \\
\hline Total & 1070 & $806(75.3)$ & 764 & 218 & $28.5(25.4-31.9)$ \\
\hline
\end{tabular}

$N$ number; globally, there was a significant difference of K76T prevalence between sites $(p<0.001)$

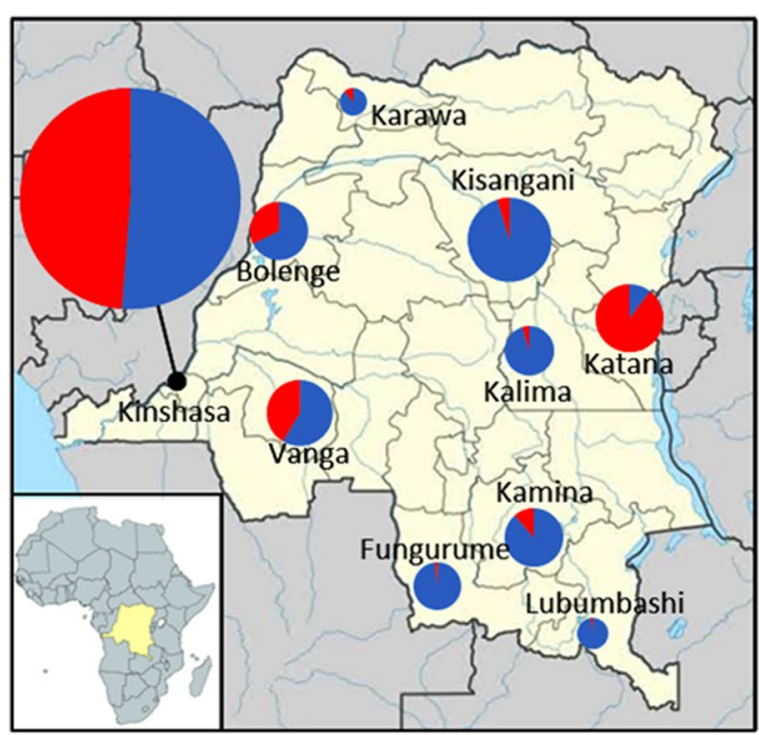

Legend

Sample size (with sequenced Pfcrt gene)

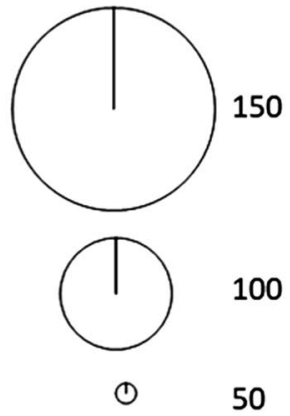

\section{Pfcrt genotype \\ K76T mutation Wild-type}

Fig. 2 Geographical distribution of K76T mutation rate across the DRC

to recover its effectiveness against the parasite. Mutations are common in parasites. However, the fitness of the mutant, which is its ability to survive compared to the wild-type parasite, may be altered as shown by a deficit of reproductive potential in a number of mutants that are otherwise viable [30]. Consequently, the majority of mutant parasites will gradually disappear from the natural population, allowing the emergence of the wild-type population [30]. This explanation could partly explain the observations of a very low prevalence of K76T mutations detected in Fungurume (1.5\%), Lubumbashi (1.8\%), Kalima (4.5\%) and Kisangani (4.7\%) in the present study.
However, this prevalence was higher in other sites such as Bolenge (32\%), Vanga (41.3\%), Kinshasa (48.8\%) and especially at Katana (89.5\%). Previous studies have reported much higher K76T rates in Kinshasa in 2008 (83.8\%) [31] and 2010 (73.2\%) [21], and in Bolenge in $2014(70.6 \%)$ [22].

The simultaneous presence of very low and high prevalence of CQ resistance could be related to different levels of CQ pressure between study sites, differing from one site to another, before and after the withdrawal of this molecule. Concerning the use of CQ in DRC, data from the DHS II in 2013-2014 revealed that in provinces 
Table 3 Repartition of the CQ-resistant PFCRT 72-76 haplotypes in the different sampling sites

\begin{tabular}{|c|c|c|c|c|}
\hline Study site & $\begin{array}{l}\text { Sample with K76T mutant } \\
\mathrm{N}\end{array}$ & $\begin{array}{l}\text { CVIET haplotype } \\
\text { N (\%) }\end{array}$ & $\begin{array}{l}\text { GVIET haplotype } \\
\text { N (\%) }\end{array}$ & $\begin{array}{l}\text { CVMET haplotype } \\
\mathrm{N}(\%)\end{array}$ \\
\hline Bolenge & 18 & $18(100)$ & $0(0.0)$ & $0(0.0)$ \\
\hline Fungurume & 1 & $1(100)$ & $0(0.0)$ & $0(0.0)$ \\
\hline Kalima & 3 & $3(100)$ & $0(0.0)$ & $0(0.0)$ \\
\hline Kamina & 8 & $8(100)$ & $0(0.0)$ & $0(0.0)$ \\
\hline Karawa & 6 & $6(100)$ & $0(0.0)$ & $0(0.0)$ \\
\hline Katana & 68 & $66(97.0)$ & $1(1.5)$ & $1(1.5)$ \\
\hline Kinshasa & 78 & 76 (97.4) & $0(0.0)$ & $2(2.6)$ \\
\hline Kisangani & 4 & $3(75.0)$ & $0(0.0)$ & $1(25.0)$ \\
\hline Lubumbashi & 1 & $0(0.0)$ & $1(100)$ & $0(0.0)$ \\
\hline Vanga & 31 & $28(90.3)$ & $2(6.5)$ & $1(3.2)$ \\
\hline Total & 218 & $209(95.9)$ & $4(1.8)$ & $5(2.3)$ \\
\hline
\end{tabular}

where our sites are located (before territorial apportionment from 11 to 26 provinces) CQ was still in use despite its withdrawal from the national policy of malaria management in 2001 [32]. Unfortunately, these DHS data have not yet been updated in the 26 current provinces and the low remaining use of CQ cannot fully explain the disparity of CQ resistance observed in different locations. Thus, further studies at the community level should be conducted to enrich the data.

The Katana site which had the highest rate of CQ resistance (89.5\%) is located in the eastern province of Sud-Kivu, where several armed militias have been warring during the last two decades. This instability in the country's security is an obstacle to good management of the use of anti-malarial drugs as recommended by the national malaria treatment policy. Lack of control of the anti-malarial supply chain could result in the use of non-recommended molecules by the population, such as CQ. In contrast, other sites such as Lubumbashi in the southeast of the country, where the security situation has been calmer, have seen a significant decrease in the prevalence of the K76T mutation in parasites. Another distinct feature of Katana is its epidemiological facies. The Katana site corresponds to the mountainous facies, where a lower malaria transmission rate results in a low rate of sexual recombination of parasite genotypes in the mosquito. As a consequence, the drug resistant genotypes become more established in the host population. However, Bushman et al. have recently suggested an alternative hypothesis based on the competition between drug-sensitive and drug-resistant parasites within the human host. This competition could slow the spread of resistance in high-transmission settings, which are marked by mixed parasite strain and genotype infections [33]. Conversely, human malaria infections consisting of multiple parasite genotypes are rarely observed in low transmission settings. Drug resistance appears and emerges from this kind of place; as previously shown in Southeast Asia, considered to be the bastion of antimalarial resistance [30]. In Africa, anti-malarial drug resistance has historically risen in the east and spreads to the rest of the continent [34]. As a reminder, the first case of resistance to CQ was reported in Tanzania [35]. The province of Kivu in the eastern Congo (where Katana is located) was the first region to report CQ resistance in the DRC [36]. In addition, a therapeutic efficacy study conducted in 2001 in the DRC, found that the city of Bukavu in Kivu contained the highest percentage (80\%) of patients who had treatment failure with CQ [2]. This finding shows a high conservation of the K76T mutation in a part of the DRC 16 years after the discontinuance of CQ as first-line therapy in the DRC national malaria policy. Future molecular studies are necessary to monitor the trends in CQ resistance marker rates and to confirm or refute this disparity across the country.

Concerning pfort haplotypes, the CVIET haplotype was predominant in isolates carrying $\mathrm{K} 76 \mathrm{~T}$ mutations in this study. However, there are many other possible combinations of polymorphisms in positions $72-76$ that include the key mutation $\mathrm{K} 76 \mathrm{~T}$ in CQ-resistant $P$. falciparum, with CVIET as the most common haplotype in Africa [10]. The single mutation in codon 76 is rarely observed in nature, suggesting that compensatory mutations in codon positions other than 76 could be required to restore the fitness of the CQ-resistant parasites bearing the K76T mutation [10]. The SVMNT haplotype associated with AQ resistance was not detected in the present study which is good news for ACT use. This haplotype has not yet been reported in the DRC [20-22] whereas it was found in neighbouring countries, such as Tanzania and Angola [12, 13]. Regular monitoring of resistance to $\mathrm{AQ}$ is required because $\mathrm{AQ}$ is the partner 
molecule in ASAQ combination therapy, which is one of the artemisinin-based combinations currently used in the country.

Out of 806 positive $P$. falciparum samples sequenced, 42 samples (5.2\%) have not given interpretable sequences. The yield of sequencing depended on several factors including the concentration of template used in the reaction. The discordance between screening test results (RDTs and thick blood test) and those of PCR P. falciparum detection will be addressed in a future publication.

\section{Limitation}

The limitation of the study is the low sample size (not representative of all the country) that results in a partial explanation of the disparity in the CQ resistance marker rate between the study sites.

\section{Conclusion}

Overall, the frequency of the $P$. falciparum CQ resistance marker has decreased significantly and no resistance marker to AQ was detected in the DRC. However, the between regions variability of CQ resistance remains high in the country. Further studies are needed for continuous monitoring of the CQ resistance level for its prospective re-use in malaria management. The absence of $\mathrm{AQ}$ resistance is in line with the use of this drug in the current DRC malaria treatment policy.

\section{Abbreviations}

WHO: World Health Organization; DRC: Democratic Republic of Congo; pfcrt: Plasmodium falciparum chloroquine resistance transporter; CQ: Chloroquine; AQ: Amodiaquine; ACT: Artemisinin-based combination therapy; DNA: Deoxyribonucleic acid; PCR: Polymerase chain reaction; RDT: Rapid diagnostic test; SP: Sulfadoxine + Pyrimethamine; ASAQ: Artesunate + Amodiaquine; AL: Artemether + Lumefantrine.

\section{Acknowledgements}

We would like to thank the staff of all collecting sites and patients for their involvement in this study.

\section{Authors' contributions}

DMY, NKK, DMM, PDM, GLM and MPH conceived and wrote the study protocol. DMY, DMM, RB and MPH carried out the molecular analyses. All authors made a major contribution in writing the manuscript. All authors read and approved the final manuscript.

\section{Funding}

This work was supported by the Académie de Recherche et d'Enseignement Supérieur (ARES), Belgium.

\section{Availability of data and materials}

All data generated and analysed during this study are included in this published article.

\section{Ethics approval and consent to participate}

The protocol and the informed consent form were approved by the Ethics Committee of the Faculty of Medicine, University of Kinshasa (Approval No: ESP MINESU 019/2016). All participants involved in the study signed an informed consent form. In cases where participants were young (children), the consent form was approved and signed by their parents or guardians.
Consent for publication

Not applicable.

\section{Competing interests}

The authors declare that they have no competing interests.

\section{Author details}

1 Department of Basic Sciences, Faculty of Medicine, University of Kinshasa, Kinshasa, Democratic Republic of Congo. ${ }^{2}$ School of Public Health, Faculty of Medicine, University of Kinshasa, Kinshasa, Democratic Republic of Congo. ${ }^{3}$ School of Public Health \& Research Institute of Health and Society, Catholic University of Louvain, 1200 Brussels, Belgium. ${ }^{4}$ Laboratory of Clinical Microbiology, University of Liège, 4000 Liège, Belgium. ${ }^{5}$ Department of Internal Medicine, Faculty of Medicine, University of Kinshasa, Kinshasa, Democratic Republic of Congo. ${ }^{6}$ National Malaria Control Programme, Kinshasa, Democratic Republic of Congo.

Received: 28 November 2019 Accepted: 13 March 2020

Published online: 20 March 2020

References

1. OMS. Stratégie technique mondiale de lutte contre le Paludisme 2016-2030. Genève: Organisation Mondiale de la Santé; 2015.

2. Kazadi WM, Vong S, Makina BN, Mantshumba JC, Kabuya W, Kebela BI, et al. Assessing the efficacy of chloroquine and sulfadoxine-pyrimethamine for treatment of uncomplicated Plasmodium falciparum malaria in the Democratic Republic of Congo. Trop Med Int Health. 2003;8:868-75.

3. WHO. Country antimalarial drug policies: by region, update. Geneva: World Health Organization; 2012. http://www.who.int/malaria/am_drug_ policies_by_region_afro/en/index. Accessed 16 Jan 2020.

4. Martin RE. The malaria parasite's chloroquine resistance transporter is a member of the drug/metabolite transporter superfamily. Mol Biol Evol. 2004;21:1938-49.

5. Tran CV. The principal chloroquine resistance protein of Plasmodium falciparum is a member of the drug/metabolite transporter superfamily. Microbiology. 2004;150:1-3.

6. Ecker A, Lehane AM, Clain J, Fidock DA. PfCRT and its role in antimalarial drug resistance. Trends Parasitol. 2012;28:504-14.

7. Lakshmanan V, Bray PG, Verdier-Pinard D, Johnson DJ, Horrocks P, Muhle RA, et al. A critical role for PfCRT K76T in Plasmodium falciparum verapamil-reversible chloroquine resistance. EMBO J. 2005;24:2294-305.

8. Cui L, Mharakurwa S, Ndiaye D, Rathod PK, Rosenthal PJ. Antimalarial drug resistance: literature review and activities and findings of the ICEMR network. Am J Trop Med Hyg. 2015:93:57-68.

9. Djimdé A, Doumbo OK, Cortese JF, Kayentao K, Doumbo S, Diourté Y, et al. A molecular marker for chloroquine-resistant falciparum malaria. N Engl J Med. 2001;344:257-63.

10. Awasthi G, Satya Prasad GBK, Satya GBK, Das A. Pfcrt haplotypes and the evolutionary history of chloroquine-resistant Plasmodium falciparum. Mem Inst Oswaldo Cruz. 2012;107:129-34.

11. Beshir K, Sutherland CJ, Merinopoulos I, Durrani N, Leslie T, Rowland $\mathrm{M}$, et al. Amodiaquine Resistance in Plasmodium falciparum malaria in Afghanistan is associated with the pfcrt SVMNT allele at codons 72 to 76 . Antimicrob Agents Chemother. 2010;54:3714-6.

12. Alifrangis M, Dalgaard MB, Lusingu JP, Vestergaard LS, Staalsoe T, Jensen ATR, et al. Occurrence of the Southeast Asian/South American SVMNT haplotype of the chloroquine-resistance transporter gene in Plasmodium falciparum in Tanzania. J Infect Dis. 2006;193:1738-41.

13. Gama BE, Pereira-Carvalho GA, Lutucuta Kosi FJ, de Oliveira NK, Fortes F, Rosenthal PJ, et al. Plasmodium falciparum isolates from Angola show the SVMNT haplotype in the pfcrt gene. Malar J. 2010;9:174.

14. Kateera F, Nsobya SL, Tukwasibwe S, Hakizimana E, Mutesa L, Mens PF, et al. Molecular surveillance of Plasmodium falciparum drug resistance markers reveals partial recovery of chloroquine susceptibility but sustained sulfadoxine-pyrimethamine resistance at two sites of different malaria transmission intensities in Rwanda. Acta Trop. 2016;164:329-36.

15. Koukouikila-Koussounda F, Jeyaraj S, Nguetse CN, Nkonganyi CN, Kokou KC, Etoka-Beka MK, et al. Molecular surveillance of Plasmodium falciparum drug resistance in the Republic of Congo: four and nine years after 
the introduction of artemisinin-based combination therapy. Malar J. 2017;16:155.

16. Lu F, Zhang M, Culleton RL, Xu S, Tang J, Zhou H, et al. Return of chloroquine sensitivity to Africa? Surveillance of African Plasmodium falciparum chloroquine resistance through malaria imported to China. Parasit Vectors. 2017;10:355.

17. Kiarie WC, Wangai L, Agola E, Kimani FT, Hungu C. Chloroquine sensitivity: diminished prevalence of chloroquine-resistant gene marker pfcrt-76 13 years after cessation of chloroquine use in Msambweni, Kenya. Malar J. 2015;14:328.

18. Afoakwah R, Boampong JN, Egyir-Yawson A, Nwaefuna EK, Verner ON, Asare KK. High prevalence of PfCRT K76T mutation in Plasmodium falciparum isolates in Ghana. Acta Trop. 2014;136:32-6.

19. Golassa L, Enweji N, Erko B, Aseffa A, Swedberg G. High prevalence of pfcrt-CVIET haplotype in isolates from asymptomatic and symptomatic patients in south-central Oromia, Ethiopia. Malar J. 2014;13:120.

20. Meshnick SR, Janko M, Tshefu AK, Taylor SM, Emch M, Antonia AL. A Crosssectional survey of Plasmodium falciparum pfcrt mutant haplotypes in the Democratic Republic of Congo. Am J Trop Med Hyg. 2014;90:1094-7.

21. Mvumbi DM, Boreux R, Sacheli R, Lelo M, Lengu B, Nani-Tuma S, et al. Assessment of pfcrt 72-76 haplotypes eight years after chloroquine withdrawal in Kinshasa, Democratic Republic of Congo. Malar J. 2013;12:459.

22. Mvumbi DM, Bobanga TL, Kayembe J-MN, Mvumbi GL, Situakibanza $\mathrm{HN}-\mathrm{T}$, Benoit-Vical F, et al. Molecular surveillance of Plasmodium falciparum resistance to artemisinin-based combination therapies in the Democratic Republic of Congo. PLoS One. 2017;12:e0179142.

23. Manguin S, Carnevale P, Mouchet J, Coosemans M, Julvez J, RichardLenoble D, et al. Biodiversity of malaria in the World. Paris: John Libbey Eurotext; 2008. p. 36.

24. Cnops L, Jacobs J, Esbroeck MV. Validation of a four-primer real-time PCR as a diagnostic tool for single and mixed Plasmodium infections. Clin Microbiol Infect. 2011;17:1101-7.

25. Laufer MK, Thesing PC, Eddington ND, Masonga R, Dzinjalamala FK, Takala $\mathrm{SL}$, et al. Return of chloroquine antimalarial efficacy in Malawi. N Engl J Med. 2006:355:1959-66.

26. Mohammed A, Ndaro A, Kalinga A, Manjurano A, Mosha JF, Mosha DF, et al. Trends in chloroquine resistance marker, Pfcrt-K76T mutation ten years after chloroquine withdrawal in Tanzania. Malar J. 2013;12:415.
27. Hemming-Schroeder E, Umukoro E, Lo E, Fung B, Tomás-Domingo P, Zhou $G$, et al. Impacts of antimalarial drugs on Plasmodium falciparum drug resistance markers, Western Kenya, 2003-2015. Am J Trop Med Hyg. 2018;98:692-9.

28. Mwanza S, Joshi S, Nambozi M, Chileshe J, Malunga P, Kabuya J-BB, et al. The return of chloroquine-susceptible Plasmodium falciparum malaria in Zambia. Malar J. 2016;15:584.

29. Frosch AE, Venkatesan M, Laufer MK. Patterns of chloroquine use and resistance in sub-Saharan Africa: a systematic review of household survey and molecular data. Malar J. 2011;10:116.

30. Laufer M, Plowe C. Withdrawing antimalarial drugs: impact on parasite resistance and implications for malaria treatment policies. Drug Resist Updates. 2004;7:279-88.

31. Mobula L, Lilley B, Tshefu AK, Rosenthal PJ. Resistance-mediating polymorphisms in Plasmodium falciparum infections in Kinshasa, Democratic Republic of the Congo. Am J Trop Med Hyg. 2009;80:555-8.

32. Republic Democratic of Congo. Demographic and Health Survey II 2013-2014. p 204.

33. Bushman M, Antia R, Udhayakumar V, de Roode JC. Within-host competition can delay evolution of drug resistance in malaria. PLoS Biol. 2018;16:e2005712.

34. Wongsrichanalai C, Pickard AL, Wernsdorfer WH, Meshnick SR. Epidemiology of drug-resistant malaria. Lancet Infect Dis. 2002;2:209-18.

35. Onori E. The problem of Plasmodium falciparum drug resistance in Africa south of the Sahara. Bull World Health Organ. 1984;62:55-62.

36. Delacollette C, Embonga B, Malengreau M. Response to chloroquine of infections with Plasmodium falciparum in the Kivu region of Zaïre. Preliminary observations. Ann Soc Belge Med Trop. 1983;63:171-3.

\section{Publisher's Note}

Springer Nature remains neutral with regard to jurisdictional claims in published maps and institutional affiliations.
Ready to submit your research? Choose BMC and benefit from:

- fast, convenient online submission

- thorough peer review by experienced researchers in your field

- rapid publication on acceptance

- support for research data, including large and complex data types

- gold Open Access which fosters wider collaboration and increased citations

- maximum visibility for your research: over 100M website views per year

At BMC, research is always in progress.

Learn more biomedcentral.com/submissions 